\title{
A THEORY-DRIVEN DESIGN RESEARCH AGENDA: EXPLORING DUAL-PROCESS THEORY
}

\author{
Cash, Philip; Daalhuizen, Jaap; Valgeirsdottir, Dagny; Van Oorschot, Robin
}

Technical University of Denmark

\begin{abstract}
Design research faces a critical 'impact gap' where the potential for scientific and practical impact is yet to be fully realised. A key means of bridging this gap is the adoption of fundamental theory from other fields to support clarification and synergy in design research. In this paper we examine one of the main candidates for adoption: dual-process theory of cognition. Cognition forms a common element across much of the design literature and leads to fundamental dual-process theories of reasoning. While dualprocess theory has started to be recognised in design research, its widespread recognition and potential utility have not been widely explored. Following a conceptual theory development approach we identify and logically describe interactions between dual-process theory and design research. We conclude the paper with a proposition of a design research framework with a core rooted in dual-process theory, and based on this, an agenda for theory-driven design research. This contributes to the debate on how to improve impact, and theoretical and scientific rigour in design research, and provides a concrete agenda for discussion and development within the community.
\end{abstract}

Keywords: Design cognition, Design methodology, Design theory, Dual-process theory, Design activity

Contact:

Cash, Philip

DTU Technical University of Denmark

DTU Management

Denmark

pcas@dtu.dk

Cite this article: Cash, P., Daalhuizen, J., Valgeirsdottir, D., Van Oorschot, R. (2019) 'A Theory-Driven Design Research Agenda: Exploring Dual-Process Theory', in Proceedings of the 22nd International Conference on Engineering Design (ICED19), Delft, The Netherlands, 5-8 August 2019. DOI:10.1017/dsi.2019.143 


\section{INTRODUCTION}

Design research faces a critical 'impact gap' i.e. the potential scientific and practical impact of design research is substantially less than the impact realised in actuality (Cash, 2018). Further, design research faces a number of challenges in supporting rapidly changing design practice (Daalhuizen, 2014a) and demonstrating the efficacy of design research based interventions (Vermaas, 2016). At the root of these challenges is a lack of cohesive and long-term theory development in design research (Cash, 2018; Love, 2002). Thus, Cash (Cash, 2018) has called for a new paradigm of theory-driven design research.

While theory-driven research has three major elements: conceptual clarity (Briggs, 2006); methodological robustness (Levin and O'Donnell, 1999); and the distillation of scientific knowledge (Hevner, 2007); they are united around a theory development agenda. Central to such an agenda is the simultaneous development of field specific theory and the identification and operationalisation of relevant theory from related fields. In particular, despite substantial opportunity for the adaption of major theories from other fields to support conceptual clarification and synergy in design research (Cash, 2018) very few have been substantially discussed. Thus, there is a major research need to identify and adapt promising theories from related fields as a basis for synthesis and development in design research.

As a starting point for this examination Hay et al.'s (2017) review of design protocol studies points to designer cognition as a key connective element linking many aspects of design research. Following the cognitive literature to its theoretical roots leads to a central discussion around dual-process theories of reasoning (Evans and Stanovich, 2013). While dual-process theory has started to be recognised in design research, by authors such as Badke-Schaub and Eris (2014) or Daalhuizen (Daalhuizen, 2014a), its widespread recognition and potential utility have not been widely discussed. Thus, this paper aims to discuss the potential for dual-process theory as a basis for development in design research.

Given this aim, it is first necessary to understand the basics of dual-process theory. Dual-process theory offers a framework for understand human thinking, integrating both intuitive, fast processing (System 1) and slower, serial processing (System 2), as well as mapping the interactions between cognitive systems and knowledge (Evans and Stanovich, 2013; Evans, 2006). More recent development of this theory offers additional insight by distinguishing two aspects of System 2: the algorithmic and reflective minds. These form two levels of deliberate processing and clarify a number of issues regarding goal-directed, reflective thinking versus the algorithmic thinking that is related to processing and attention. This is particularly relevant as reflection is a core interest in the design literature (Dorst, 2011; Schön, 1983), and relates to discussions of metacognition (Christensen and Ball, 2017; Valgeirsdottir and Onarheim, 2017). Ultimately, System 1 and System 2 continuously interact in order to shape thinking and behaviour.

To achieve our research aim we first provide an overview of the current theoretical landscape in design research. Subsequently we discuss three critical perspectives on the potential adoption of dual-process theory in design research: design creativity, design methodology, and the link between design and other fields. Finally, we distil a dual-process-based agenda for future theory-driven design research.

\section{THE DESIGN RESEARCH LANDSCAPE}

Given the sparsity of foundational theory in the current design literature, a conceptual approach is needed in order to set the basis for future empirical work (Wacker, 1998). Through this approach we aim to identify and logically describe interactions between dual-process theory and design research. This follows two main steps: an overview of theoretical discussion in the current design research literature (Section 2), followed by a deeper dive into key intersections between dual-process theory and design research themes (Section 3).

In order to understand the potential for dual-process theory in design research it is necessary to gain an overview of current theoretical foci in the design literature. As such, a systematic review of Design Studies was undertaken using the keyword "theory" in the full text, between 2004 and 2016. While this scope is limited, Design Studies is the most theoretically focused and mature journal in design research, as well as the highest ranked (Gemser et al., 2012). Further, it has formed the focus of a number of major reviews. Together this makes recent Design Studies articles an ideal dataset for this work. Theories were identified based on reference usage in order to provide insight into the range of topics being discussed, and their various theortical foundations. Further, it is important to note that, based on the extensive review of Cash (Cash, 2018), it is already known that theory usage is quite 
varied in the design literature and there are no widely accepted theories. Thus, our review provides an important step towards identifying overall themes and concepts discussed in design research. As such, the aim of this overview was threefold:

1. Provide an overview of potential overlap between design research and dual-process theory.

2. Provide a context for identifying specific elements through which design research and dualprocess theory can be linked.

3. Provide a basis for discussion the potential synergy effects provided by adoption of dual-process theory in design research.

The review resulted in the identification of 101 specific theories, ranging from designer and user focused use of dual-process cognition to artefact focused use of shape grammars. Further, 19 more general bodies of research were mentioned without identifying the specific theory being referenced e.g. general allusions to 'theory of style' or 'theory of planning'. Finally, there were repeated references to three methodological theories, e.g. grounded theory. The 19 more general theoretical allusions and three methodological theories were excluded at this stage in order to focus on the subject specific aspects of design research at a degree of detail suitable for concrete comparison. The full list of theories is provided in Table 1; citations are omitted for space reasons.

Table 1. Design research in 101 theories

\begin{tabular}{|c|c|c|c|c|}
\hline $\begin{array}{c}\text { Action regulation } \\
\text { theory }\end{array}$ & $\begin{array}{l}\text { Cue summation } \\
\text { theory }\end{array}$ & $\begin{array}{l}\text { Marxist theory of } \\
\text { value }\end{array}$ & $\begin{array}{l}\text { Social shaping of } \\
\text { technology }\end{array}$ & Theory of flow \\
\hline Activity theory & $\begin{array}{c}\text { Cultural } \\
\text { dimensions theory }\end{array}$ & $\begin{array}{c}\text { Media richness } \\
\text { theory }\end{array}$ & Soundscape theory & $\begin{array}{l}\text { Theory of human } \\
\text { problem solving }\end{array}$ \\
\hline $\begin{array}{l}\text { Actor-network } \\
\text { theory }\end{array}$ & $\begin{array}{l}\text { Direct perception } \\
\text { theory }\end{array}$ & $\begin{array}{c}\text { Media } \\
\text { synchronicity }\end{array}$ & Speech act theory & $\begin{array}{c}\text { Theory of } \\
\text { Intentionality }\end{array}$ \\
\hline Agency theory & $\begin{array}{l}\text { Dual-process } \\
\text { theory }\end{array}$ & $\begin{array}{c}\text { Motivation- } \\
\text { hygiene theory / } \\
\text { two-factor theory }\end{array}$ & $\begin{array}{c}\text { Spreading } \\
\text { activation theory of } \\
\text { memory }\end{array}$ & $\begin{array}{c}\text { Theory of } \\
\text { inventive problem } \\
\text { solving / TRIZ }\end{array}$ \\
\hline $\begin{array}{l}\text { Analogical } \\
\text { reasoning }\end{array}$ & Expectancy theory & Object theory & $\begin{array}{c}\text { Spreading } \\
\text { activation theory of } \\
\text { semantic } \\
\text { processing }\end{array}$ & Theory of mind \\
\hline Appraisal theory & $\begin{array}{c}\text { Expectancy-value } \\
\text { theory }\end{array}$ & $\begin{array}{c}\text { Opportunistic } \\
\text { assimilation theory }\end{array}$ & $\begin{array}{c}\text { Structure-mapping } \\
\text { theory }\end{array}$ & $\begin{array}{c}\text { Theory of multiple } \\
\text { intelligences }\end{array}$ \\
\hline $\begin{array}{c}\text { Associative } \\
\text { learning theory }\end{array}$ & $\begin{array}{c}\text { Experiential } \\
\text { learning theory }\end{array}$ & $\begin{array}{c}\text { Organizational } \\
\text { creativity }\end{array}$ & $\begin{array}{c}\text { Structures in } \\
\text { language theory }\end{array}$ & Theory of place \\
\hline $\begin{array}{c}\text { Biopsychosocial } \\
\text { human motivation }\end{array}$ & Fuon theory & $\begin{array}{l}\text { Performance } \\
\text { theory }\end{array}$ & $\begin{array}{l}\text { Systemic- } \\
\text { functional } \\
\text { linguistics }\end{array}$ & $\begin{array}{c}\text { Theory of positive } \\
\text { affect }\end{array}$ \\
\hline C-K Theory & Game theory & Play theory & $\begin{array}{c}\text { Systemic- } \\
\text { functional theory }\end{array}$ & $\begin{array}{c}\text { Theory of shared } \\
\text { mental models }\end{array}$ \\
\hline Catastrophe theory & $\begin{array}{c}\text { General systems } \\
\text { theory }\end{array}$ & Practice theory & $\begin{array}{l}\text { Theory of } \\
\text { abduction }\end{array}$ & $\begin{array}{c}\text { Theory of shared } \\
\text { values }\end{array}$ \\
\hline $\begin{array}{c}\text { Cognitive load } \\
\text { theory }\end{array}$ & $\begin{array}{l}\text { Goal orientation } \\
\text { theory }\end{array}$ & $\begin{array}{l}\text { Reader-response } \\
\text { theory }\end{array}$ & $\begin{array}{c}\text { Theory of } \\
\text { affordances / } \\
\text { affordance theory }\end{array}$ & $\begin{array}{l}\text { Theory of } \\
\text { structuration }\end{array}$ \\
\hline $\begin{array}{l}\text { Commitment-trust } \\
\text { theory }\end{array}$ & Graph theory & $\begin{array}{l}\text { Recognition-by- } \\
\text { components theory }\end{array}$ & Theory of artefacts & $\begin{array}{c}\text { Theory of technical } \\
\text { systems }\end{array}$ \\
\hline Complexity theory & $\begin{array}{c}\text { Graphical and } \\
\text { linguistic reasoning }\end{array}$ & $\begin{array}{c}\text { Reconstructive } \\
\text { memory }\end{array}$ & $\begin{array}{c}\text { Theory of bounded } \\
\text { rationality }\end{array}$ & $\begin{array}{c}\text { Theory of value } \\
\text { transfer }\end{array}$ \\
\hline $\begin{array}{l}\text { Computational } \\
\text { theory of shapes }\end{array}$ & $\begin{array}{c}\text { Image schema } \\
\text { theory }\end{array}$ & $\begin{array}{c}\text { Self-determination } \\
\text { theory }\end{array}$ & $\begin{array}{c}\text { Theory of } \\
\text { capabilities }\end{array}$ & Trait theory \\
\hline $\begin{array}{l}\text { Conceptual } \\
\text { combination }\end{array}$ & $\begin{array}{l}\text { Information } \\
\text { processing theory }\end{array}$ & Set theory & $\begin{array}{l}\text { Theory of case } \\
\text { based reasoning }\end{array}$ & $\begin{array}{l}\text { Transformational } \\
\text { leadership theory }\end{array}$ \\
\hline
\end{tabular}




\begin{tabular}{|c|c|c|c|c|}
\hline Conflict theory & Information theory & Sign theory & $\begin{array}{l}\text { Theory of cue } \\
\text { summation }\end{array}$ & Utility theory \\
\hline $\begin{array}{l}\text { Constructivist } \\
\text { theory of cognition }\end{array}$ & $\begin{array}{l}\text { Institutional } \\
\text { isomorphism }\end{array}$ & $\begin{array}{c}\text { Situated simulation } \\
\text { theory }\end{array}$ & $\begin{array}{l}\text { Theory of digital } \\
\text { tectonics }\end{array}$ & $\begin{array}{l}\text { Vygotsky's Theory } \\
\text { of Creativity }\end{array}$ \\
\hline $\begin{array}{c}\text { Conversation } \\
\text { theory }\end{array}$ & $\begin{array}{c}\text { Interpersonal } \\
\text { deception theory }\end{array}$ & $\begin{array}{c}\text { Situational } \\
\text { contingency theory }\end{array}$ & $\begin{array}{c}\text { Theory of dynamic } \\
\text { memory }\end{array}$ & \\
\hline $\begin{array}{l}\text { Correspondence } \\
\text { theory of truth }\end{array}$ & $\begin{array}{l}\text { Latent semantic } \\
\text { analysis theory }\end{array}$ & $\begin{array}{c}\text { Social interaction } \\
\text { theory }\end{array}$ & $\begin{array}{c}\text { Theory of } \\
\text { emergence }\end{array}$ & \\
\hline $\begin{array}{l}\text { Creative action in } \\
\text { multiple social } \\
\text { domains }\end{array}$ & $\begin{array}{l}\text { Legitimation code } \\
\text { theory }\end{array}$ & $\begin{array}{l}\text { Social learning } \\
\text { theory }\end{array}$ & $\begin{array}{l}\text { Theory of } \\
\text { expectations }\end{array}$ & \\
\hline $\begin{array}{c}\text { Creative segment } \\
\text { theory }\end{array}$ & $\begin{array}{c}\text { Long-term working } \\
\text { memory }\end{array}$ & $\begin{array}{c}\text { Social network } \\
\text { theory }\end{array}$ & Theory of fixation & \\
\hline
\end{tabular}

Mapping the theories in Table 1 to their usage in design research illustrates the potential value of dualprocess theory as a means of connecting bodies of design research. Specifically, it connects theories dealing with the design team, user behaviour and managerial behaviour. Together these cover the majority of theory references in design research ( 56 theories).

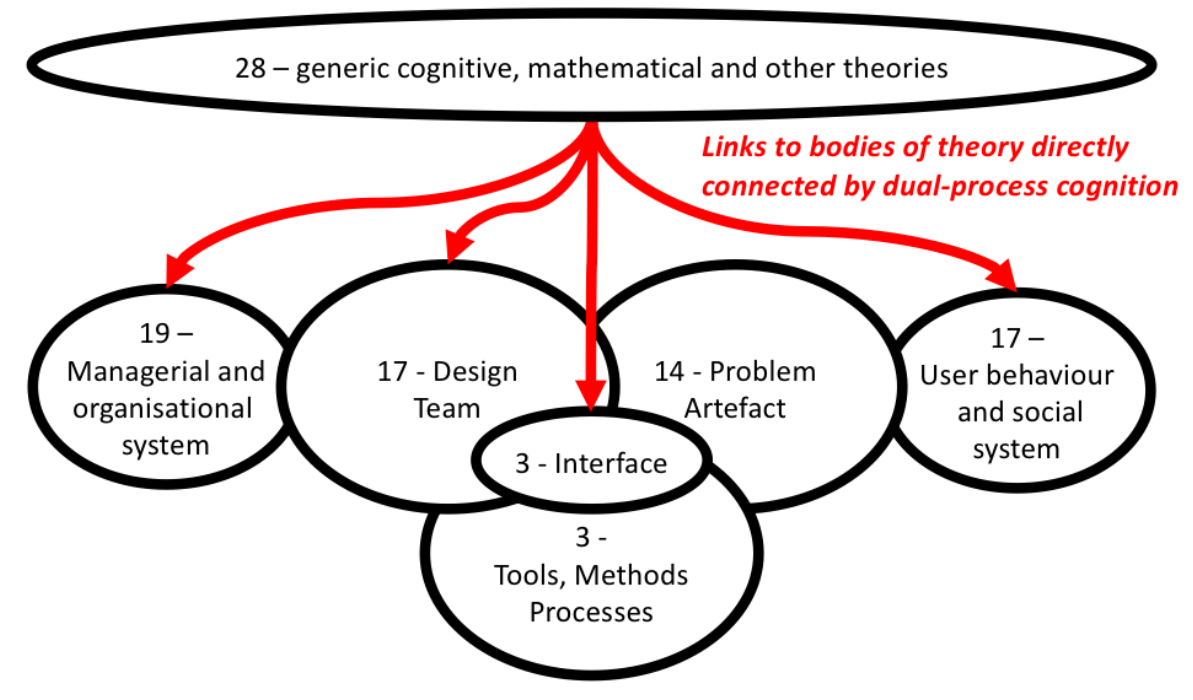

Figure 1. Initial overview of theories with respect to thematic topics in design research

\section{THREE PERSPECTIVES ON DUAL-PROCESS THEORY IN DESIGN RESEARCH}

Contrasting the usage of theories illustrated in Figure 1 against dual-process theory reveals three distinct areas of potential, each of which are discussed below using an illustrative design research theme:

1. Elaborating and integrating existing design research e.g. creativity and activity.

2. Closing critical gaps in current design research theory e.g. methodology.

3. Supporting impact in other fields e.g. design, innovation and entrepreneurship.

\subsection{Elaborating and integrating existing design research: Creativity and activity}

In Kozbelt et al.'s (2010) 'Theories of Creativity', cognition is identified as a foundation for understanding creative production, and links many of the theories associated with creativity in the design literature (Table 1). At the root of this cognitive perspective is the work of Guilford (1968), who both formalised much of creativity research and defined divergent and convergent modes of cognition. Divergent cognition is the ability to generate alternatives, which is a typical measure of creative potential, and convergent cognition is the ability to distil an output from prior divergent alternatives (Runco, 2011). Together, these form the keys to creativity through novelty and usefulness (Runco and Jaeger, 2012). Generally, designers move through alternating rounds of divergent/convergent cognition to find the problem, generate solutions and implement these, as proposed by Basadur et al. (1982). While 
this combination of alternating divergent/convergent cognition has been widely recognised and operationalised in e.g. the Double Diamond model (Design Council, 2005), further decomposition of the creative process has been limited by the lack of granularity in this conceptualisation.

In this context, dual-process theory provides a basis for further decomposing divergent/convergent creative cognition (Augello et al., 2016). Specifically, it allows researchers to elaborate a number of mechanisms underpinning creative production.

First, the ability to make associations, and subsequently form associative chains, is a critical component in divergent cognition (Mednick, 1962). Specifically, Mednick (1962) predicted that associations found later in the associative chain i.e. remote associations, would be more original than those found close to the source, or close associations. However, this divergent process is often stymied by fixation, where a person continuously falls back on previously thought-of solutions (Runco and Chand, 1995). Recommendations for relieving fixation have focused on taking cognitively engaging breaks from the task at hand in order to foster incubation of new perspectives and ideas (Ellwood et al., 2009; Tan et al., 2015). Here, dual-process theory provides a framework for explaining the link between association, fixation and its amelioration. Specifically, System 1 provides immediate associations to a given stimulus based on prior experience and rapid evaluation of the current situation (Evans and Stanovich, 2013), as such, if effort is not expended to override this association it will bias thinking, resulting in the designer arriving at similar solutions again and again. This is formalised as serial associative cognition with a focal bias, where hypothetical thinking has not been 'decoupled' and thus produces outputs close to the input (Stanovich, 2009). As such, efforts to relieve fixation can be understood as attempting to break this underlying bias by taking a break and re-contextualising the creative task in order to trigger a new System 1 association. Thus, dual-process theory allows for a more nuanced understanding of the mechanisms at play and subsequently allows researchers to devise alternative or more effective strategies for resolving issues such as fixation.

Second, the structural understanding of cognition provided by dual-process theory helps explain the relationship between creative performance and metacognition (Feldhusen, 1995; Jausovec, 1994). Metacognition describes the monitoring and control of cognition (Flavell, 1979); it is thinking about thinking (Welling, 2007). The application of metacognition in creativity has been operationalised by Valgeirsdottir et al. (2016) as 'process awareness'. This is defined as creativity-specific metacognition that designers use to facilitate their processes by planning, monitoring and reflecting on the creative process. This enables designers to be more deliberate in the application of tactics and strategies in addition to being aware of the influences of external stimuli. As such, process awareness links to the reflective mind of System 2 (Evans and Stanovich, 2013), which provides a structure for understanding how a designer might identify problematic processes, such as fixation, and deliberately alter their cognition or behaviour in order to address these.

Finally, metacognition and the reflective mind connect to discussions of how to bring synergy to conceptualisations of design activity, where for example, Cash and Kreye (2017) describe metacognitive uncertainty perception as a key driver of changes in design behaviour. As with process awareness this metacognitive mechanism links to aspects of System 2 and thus contributes to understanding the relationship between design creativity and activity. Similarly, design activity has been variously linked information processing, reflection and intuition (Badke-Schaub and Eris, 2014; Cash and Kreye, 2017; Hay et al., 2017; Schön, 1983), which can all be conceptualised with respect to the elements of dual-process theory (Evans and Stanovich, 2013; Evans, 2006). Thus, in addition to offering potential for describing specific aspects of design creativity dual-process theory provides a common framework suitable also for describing a range of conceptualisations of design activity.

The structure provided by System 1 and System 2 elaborates and connects critical procedural concepts such as 'process awareness' (Valgeirsdottir et al., 2016) and uncertainty perception (Christensen and Ball, 2017) as well as more specific concepts of divergence/convergence, association and fixation, inspiration and intuition (Badke-Schaub and Eris, 2014). Further, the robustness of dual-process theory makes it suitable for simulation and thus forms the basis for important emergent discussions of how to model and structure understanding of creativity (Augello et al., 2016) and activity in design (Cash and Kreye, 2017). As such, it can be concluded that dual-process theory provides a common lens for understanding a range of related design concepts and thus provides a basis for integrating these discussions in a structured manner. 


\subsection{Closing critical gaps in current design research theory: Methodology}

Design methodology as a field of study has existed at the core of design research for at least six decades, and emerged from pivotal moments like the conference on design methods in 1963 in London or the WDK (Workshop Design-Konstruktion) meetings that formed the precursor to the ICED conference series. The growth of design methodology and the subsequent proliferation of methods has been marked by sustained criticism of the disappointing impact of those methods in practice and education (Alexander, 1971; Andreasen, 2011; Dorst, 2008; Daalhuizen, 2014a; Daalhuizen and Badke-Schaub, 2011; Jones, 1977). Given these disappointments, efforts have been made to systematize the development of methods and to emphasize the importance of robust criteria for their evaluation (Vermaas, 2016). Yet design methodology is still lacking a specific theory of method usage, which explains methods' properties, and how their impact might be tested (Table 1). Thus, there is a need for a theory of method usage that can both explain empirical findings and conceptually dissolve the diversity in discussion surrounding methods and their use.

As a starting point for resolving this gap a number of authors have identified designers and their cognitive processes as a unifying element linking design methodology discussions. Specifically, Daalhuizen (Daalhuizen, 2014a) reconceptualised methods as mental tools, rather than prescriptive processes that directly impact design outcomes. Supporting this reconceptualising has been research emphasising the importance of method mindset (Andreasen, 2003; Andreasen et al., 2015) and individual differences in method use and effect (Daalhuizen et al., 2014). Thus, this reconceptualization places designers and their cognitive processes at the centre of the method usage phenomenon, and points to links between design methodology and cognitive theory.

Dual-process theory forms an ideal candidate for elaborating this link, and offers a number of opportunities for furthering the field; in relation to method development, method testing, and organizing the widely varying empirical descriptions of method errors. Specifically, dual-process theory offers different pathways linking System 1 and 2 (Evans and Stanovich, 2013), able to explain the basic steps required of a designer (as in the creative association or relieving fixation examples in Section 3.1), as well as the overall framing of the method with respect to the designer's world view. Thus, dual-process theory offers the potential for developing a theory method usage that can describe both the specific cognitive processes that methods aim to support, as well as the specific procedures, strategies, goals, beliefs and values they might influence to the individual user, as outlined in (Daalhuizen, 2014b).

In terms of method development and testing, a theory of method usage grounded in dual-process theory offers specific operationalized pathways for how methods can affect designers' thinking, as well as a taxonomy of systematic errors that are likely to occur and should be avoided when the method is used. This is comparable to the basic taxonomy of thinking errors derived from dual-process theory research (Stanovich, 2009). Thus, dual-process theory provides an opportunity to more precisely target the working mechanisms being triggered during method usage as well as the potential for identifying systematic errors, rooted in these mechanisms, that might occur when methods are used.

The fundamental nature of the cognitive mechanisms provided by dual-process theory offers a consistent means of describing method usage, examining method's effects, and testing their efficacy. Further, this dissolves much of variety in method descriptions across the literature (Andreasen et al., 2015; Daalhuizen, 2014a), and provides a framework of mechanisms and systematic errors that can be tested in the design method context (Stanovich, 2009). As such, dual-process theory offers a means of closing a critical gap in design research theory, and suggests how a theory of method usage could facilitate a leap forward for design methodology.

\subsection{Supporting impact in other fields: Design, innovation and entrepreneurship}

Finally, in order to support wider impact across fields design faces substantial challenges in translating its insights into defined, communicable constructs able to be interpreted and adopted by others (Cash, 2018). Here, authors, such as Van Oorschot (2018), have taken a direct approach to dissolving the divide between design and other fields by carrying out research deliberately contrasting different perspectives, specifically between design, innovation and entrepreneurship. The research of Van Oorschot (2018) is important because the issues he discusses are characteristic of the general issues faced by design researchers in this context.

For example, while 'design thinking' is used across fields it still forms a problematic barrier to communication due to conceptual inconsistency. Johansson-Sköldberg et al. (2013) describe the biggest challenge in design thinking as "Design thinking is often equated to creativity: Sometimes the 
popular version 'design thinking' is presented as a way to make managers think more creatively. But being creative is only part of the competence and practice of the designer's work." (JohanssonSköldberg et al., 2013) and "Design thinking is often equated to a toolbox: Sometimes the popular versions focus on the designer's specific methods taken out of context, as tools ready for use, but the person using the tools must have the knowledge and skill - competence that comes with training - to know when to use them (Johansson-Sköldberg et al., 2013). Further, Carlgren et al. (2016) highlight how Brown (2008) defines design thinking in multiple ways within the same article. Brown discusses a 'team-based approach to innovation' (Brown, 2008, p. 1), a discipline (Brown, 2008, p. 2), and part of a development process (Brown, 2008). Thus, there is substantial difficulty in linking insights from across research communities as demonstrated by Van Oorschot (Van Oorschot, 2018), even around relatively well established concepts.

The above example illustrates a critical issue affecting design researchers seeking to apply design insights to other fields i.e. a more robust understanding is needed than general descriptions, such as Design Thinking, can offer. Given this issue Van Oorschot comes to a similar realisation as research on human work and design activity (Bedny and Harris, 2005; Cash and Kreye, 2017). Specifically, design bridges individual cognitive and social group perspectives (Grossman et al., 2017) and thus, core 'design processes' are embedded in the broader flow of innovation or entrepreneurial work (Cash et al., 2015; von Stamm, 2004). Here, Van Oorschot characterises the interactions between these elements using existing constructs from the design literature in order to offer insights for entrepreneurship, however, he also recognizes that the utility of such an approach is limited by the degree to which such interactions can be described in common fundamental terms.

As illustrated in Sections 3.1 and 3.2 dual-process theory provides just such a fundamental terminology with the potential to connect research areas sharing cognition as a common perspective. For example, design, innovation and entrepreneurship all share discussions of practitioner cognition and its impact on work processes (Dorst, 2011; Van Oorschot, 2018). As such, dual-process offers a common language of concepts and processes suitable for 'translating' findings between fields, operationalising insights in common terms and describing interactions between design and other work processes.

\section{A DUAL-PROCESS-BASED AGENDA FOR DESIGN RESEARCH}

Based on the above discussions it is possible to understand dual-process theory's potential benefits for the design research literature. Specifically, it offers:

- An accepted common language for translating design insights into other applied fields

- A synergistic lens that connects major design and creativity concepts.

- A potential means of closing critical gaps in understanding in design research. In particular, related to how designers understand and use design methods, and how they are developed.

These potential benefits are further enhanced by the robust conceptualisation, commonality in application, and extant empirical support for dual-process theory. These characteristics coupled with Section 3 illustrate how dual-process theory could support efforts to connect disparate discussions in the design research literature, not only in design cognition but more broadly across the field, including understanding of method usage, artefact interaction and representation, and more. Notably, of the 101 theories identified in Table 1 at least 37 deal explicitly with aspects of designer or user behaviour that can be directly connected to cognition. This aligns well with recent works calling for synergy in design cognition (Hay et al., 2017) and design activity (Cash and Kreye, 2017). Our conceptualisation of dualprocess theory as a potential core for human centric design research is illustrated in Figure 2.

Based on the conceptualisation in Figure 2, and the theory-driven research framework described by Cash (Cash, 2018) it is possible to propose a dual-process-based agenda for future theory-driven design research, as illustrated in Figure 3. Specifically, we identify five major research themes needed to support adoption and development of dual-process theory in the design context. This follows the basic elements of theory development outlined by Cash (Cash, 2018) and provide a roadmap for integrating dual-process and design research insights. Together the five themes outlined in Figure 3 cover the description and contextualisation of dual-process phenomena in the design context; the clarification and alignment of concepts and terminology; the identification of relationships between core design topics e.g. design cognition and method usage; the development of predictive power in design research; and ultimately, the structured testing of predictions, based in dual-process design theory, in both the academic and real world contexts. 


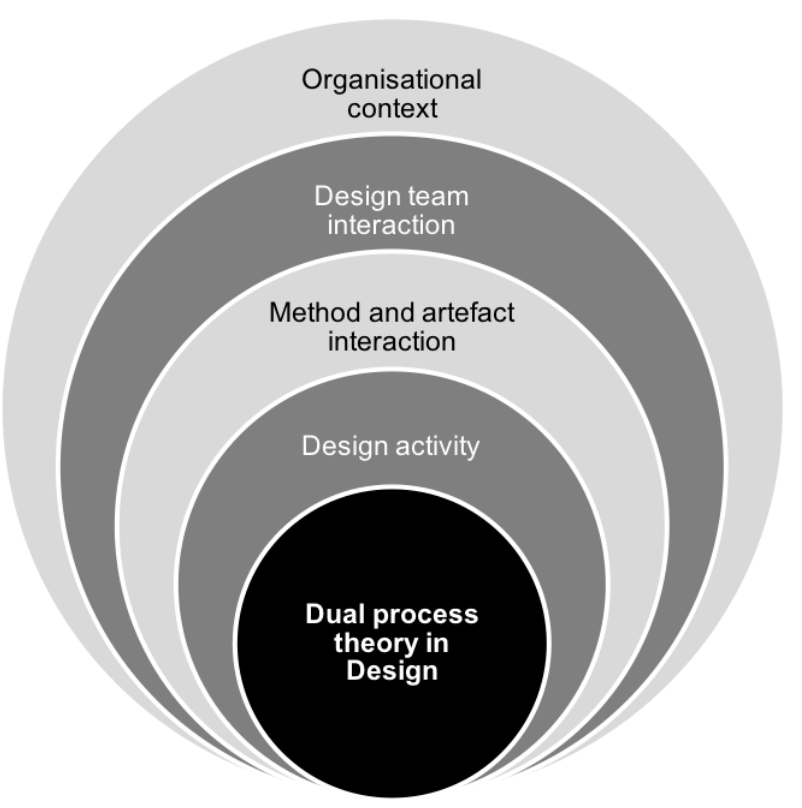

Figure 2. Dual-process theory in design as a core platform for understanding human centric design research

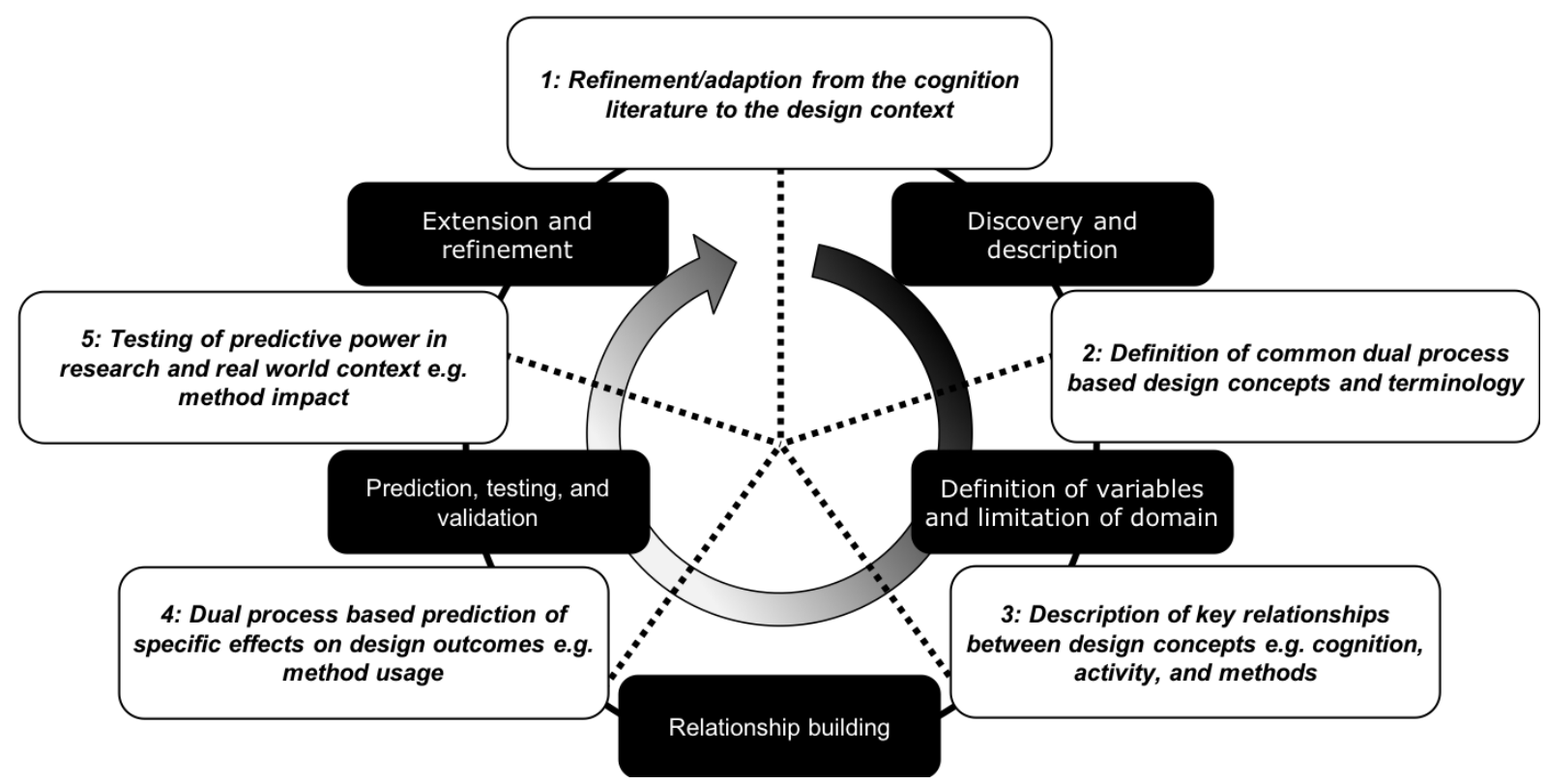

Figure 3. A dual-process-based agenda for theory-driven design research

\section{A BALANCED VIEW}

While this work takes cognition and dual-process theory as a starting point, this is not the only perspective that could yield benefits for the design research field. For example, as social process become more dominant and organisation level increases dual-process theory might be superseded by candidates from the social science domain. Similarly, there are other perspectives on design rooted in process structure or the design artefact itself. As such, dual-process theory should not be considered an 'only option' but rather one potentially fruitful direction for design research development. More generally, we ask design researchers to consider the questions raised and discussed in this paper i.e. how to bring conceptual clarity and synergy to design research, how to address major gaps in current design theory, and how to achieve greater impact in other fields. These aims can be achieved in a number of ways, including independent development of robust design theory, however, this work highlights the substantial benefits possible from the adoption of already existing theory, particularly, where this is as well established and widely relevant as dual-process theory. 


\section{CONCLUSIONS}

In conclusion this work aimed to discuss the potential for dual-process theory to form a basis for synthesis and development in design research. To this end we have identified and discussed a number of potential benefits surrounding the adoption of dual-process theory as a core for human centric design research. Ultimately this has resulted in our proposition of a design research framework with a core rooted in dual-process theory, and based on this, an agenda for theory-driven design research going forward. This contributes to the debate on how to improve impact, and theoretical and scientific rigour in design research, and provides a concrete agenda for discussion and development within the community.

\section{REFERENCES}

Alexander, C. (1971), "State of art in design methodology: interview with C. Alexander", DMG Newsletter, pp. 3-7.

Andreasen, M.M. (2003), "Improving design methods usability by a mindset approach", In: Lindemann, U. (Ed.), Human Behaviour in Design, Springer, Berlin Heidelberg, pp. 209-218.

Andreasen, M.M. (2011), “45 years with design methodology”, Journal of Engineering Design, Vol. 22 No. 5, pp. 293-332.

Andreasen, M.M., Thorp Hansen, C. and Cash, P. (2015), Conceptual Design: Interpretations, Mindset and Models, Conceptual Design: Interpretations, Mindset and Models, Springer, available at: https://doi.org/10.1007/978-3-319-19839-2.

Augello, A., Infantino, I., Lieto, A., Pilato, G., Rizzo, R. and Vella, F. (2016), “Artwork creation by a cognitive architecture integrating computational creativity and dual process approaches", Biologically Inspired Cognitive Architectures, Vol. 15, pp. 74-86.

Badke-Schaub, P. and Eris, O. (2014), "A Theoretical Approach to Intuition in Design: Does Design Methodology Need to Account for Unconscious Processes?", In: Chakrabarti, A. and Blessing, L.T.M. (Eds.), An Anthology of Theories and Models of Design: Philosophy, Approaches and Empirical Explorations, Springer London, London, pp. 353-370.

Basadur, M., Graen, G.B. and Green, S.G. (1982), "Training in creative problem solving: Effects on ideation and problem finding and solving in an industrial research organization", Organizational Behavior and Human Performance, Vol. 30 No. 1, pp. 41-70.

Bedny, G.Z. and Harris, S.R. (2005), "The systemic-structural theory of activity: Applications to the study of human work", Mind, Culture, and Activity, Vol. 12 No. 2, pp. 128-147.

Briggs, R.O. (2006), "On theory-driven design and deployment of collaboration systems", International Journal of Human-Computer Studies, Vol. 64 No. 7, pp. 573-582.

Brown, T. (2008), "Design thinking", Harvard Business Review, Vol. 2008 No. June, pp. 1-9.

Carlgren, L., Rauth, I. and Elmquist, M. (2016), "Carlgren rauth elmquist 2016 cim framing design thinking", Creativity and Innovation Management, Vol. 25 No. 1, pp. 38-57.

Cash, P. (2018), "Developing theory-driven design research", Design Studies, Vol. 56 No. May, pp. 84-119.

Cash, P., Hicks, B. and Culley, S. (2015), "Activity theory as a means for multi-scale analysis of the engineering design process: A protocol study of design in practice", Design Studies, Vol. 38 No. May, pp. 1-32.

Cash, P. and Kreye, M.E. (2017), "Uncertainty Driven Action (UDA) model: A foundation for unifying perspectives on design activity", Design Science, Vol. 3 No. e26, pp. 1-41.

Christensen, B.T. and Ball, L.J. (2017), "Fluctuating Epistemic Uncertainty in a Design Team as a Metacognitive Driver for Creative Cognitive Processes", In: Christensen, B.T., Ball, L.J. and Halskov, K. (Eds.), Analysing Design Thinking: Studies of Cross-Cultural Co-Creation, CRC Press, pp. 249-270.

Dorst, K. (2008), “Design research: a revolution-waiting-to-happen”, Design Studies, Elsevier, Vol. 29 No. 1, pp. $4-11$.

Dorst, K. (2011), “The core of 'design thinking' and its application”, Design Studies, Elsevier Ltd, Vol. 32 No. 6, pp. 521-532.

Daalhuizen, J. (2014a), Method Usage in Design: How Methods Function as Mental Tools for Designers, Delft University of Technology.

Daalhuizen, J. (2014b), Method Usage in Design, Delft University of Technology.

Daalhuizen, J. and Badke-Schaub, P. (2011), "The use of methods by advanced beginner and expert industrial designers in non-routine situations: a quasi-experiment", International Journal of Product Development, Vol. 15 No. 1/2/3, p. 54.

Daalhuizen, J., Person, O. and Gattol, V. (2014), “A personal matter? An investigation of students' design process experiences when using a heuristic or a systematic method", Design Studies, Vol. 35 No. 2, pp. 133-159.

Ellwood, S., Pallier, G., Snyder, A. and Gallate, J. (2009), “The incubation effect: hatching a solution?", Creativity Research Journal, Vol. 21 No. 1, pp. 6-14. 
Evans, J. and Stanovich, K.E. (2013), "Dual-process theories of higher cognition: advancing the debate", Perspectives on Psychological Science, Vol. 8 No. 3, pp. 223-241.

Evans, J.S.B.T. (2006), "The heuristic-analytic theory of reasoning: Extension and evaluation”, Psychonomic Bulletin \& Review, Vol. 13 No. 3, pp. 378-395.

Feldhusen, J.F. (1995), "Creativity: A knowledge base, metacognitive skills, and personality factors", The Journal of Creative Behavior, Vol. 29 No. 4, pp. 255-268.

Flavell, J.H. (1979), "Metacognition and cognitive monitoring: A new area of cognitive-developmental inquiry", American Psychologist, Vol. 34 No. 10, pp. 906-911.

Gemser, G., De Bont, C., Hekkert, P. and Friedman, K. (2012), "Quality perceptions of design journals: The design scholars' perspective”, Design Studies, Elsevier Ltd, Vol. 33 No. 1, pp. 4-23.

Grossman, R., Friedman, S. and Kalra, S. (2017), "Teamwork processes and emergent states", In: Salas, E., Rico, R. and Passmore, J. (Eds.), The Wiley Blackwell Handbook of the Psychology of Team Working and Collaborative Processes, 1st ed., John Wiley \& Sons, pp. 245-269.

Guilford, J.P. (1968), Creativity, Intelligence, and Their Educational Implications, Robert Knapp, RR Knapp San Diego, San Diego, CA.

Hay, L., Duffy, A., McTeague, C., Pidgeon, L., Vuletic, T. and Grealy, M. (2017), “A systematic review of protocol studies on conceptual design cognition: Design as search and exploration”, Design Science, Vol. 3 No. Visser 2004, p. e10.

Hevner, A.R. (2007), “A three cycle view of design science research”, Scandinavian Journal of Information Systems, Vol. 19 No. 2, pp. 87-92.

Jausovec, N. (1994), “The influence of metacognition on problem-solving performance", Review of Psychology, Vol. 1 No. 1, pp. 21-28.

Johansson-Sköldberg, U., Woodilla, J. and Cetinkaya, M. (2013), "Design thinking : Past , present and possible futures", Creativity and Innovation Management, Vol. 22 No. 2, pp. 121-146.

Jones, J.C. (1977), "How my thoughts about design methods have changed during the years", Design Methods and Theories: Journal of DMG and DRS, Vol. 11 No. 1.

Kozbelt, A., Beghetto, R. and Runco, M.A. (2010), “Theories of Creativity”, In: Kaufman, J.C. and Sternberg, R.J. (Eds.), The Cambridge Handbook of Creativity, Cambridge University Press, Cambridge, MA, pp. $20-47$.

Levin, J.R. and O’Donnell, A.M. (1999), “What to do about educational research's credibility gaps?”, Issues in Education, Vol. 5 No. 2, pp. 177-229.

Love, T. (2002), "Constructing a coherent cross-disciplinary body of theory about designing and designs: some philosophical issues", Design Studies, Vol. 23 No. 3, pp. 345-361.

Mednick, S.A. (1962), "The associative basis of the creative process", Psychological Review, Vol. 69 No. 3 , pp. 220-232.

Van Oorschot, R. (2018), Entrepreneurship Education through Design: Exploring Different Design Perspectives to Understand and Educate the Business Proposition Development Process in New High-Tech Ventures, TU Delft.

Runco, M.A. (2011), “Personal creativity”, In: Runco, M.A. and Pritzker, S.R. (Eds.), Encyclopedia of Creativity, 2nd ed., Elsevier, pp. 220-223.

Runco, M.A. and Chand, I. (1995), “Cognition and creativity”, Educational Psychology Review, Vol. 7 No. 3 , pp. 243-267.

Runco, M.A. and Jaeger, G.J. (2012), “The standard definition of creativity”, Creativity Research Journal, Vol. 24 No. 1, pp. 92-96.

Schön, D.A. (1983), The Reflective Practitioner: How Professionals Think in Action, Harper Torchbooks, New York, USA.

von Stamm, B. (2004), “Innovation: What's design got to do with it?”, Design Management Review, Vol. 15 No. 1, pp. 10-19.

Stanovich, K.E. (2009), "Distinguishing the reflective, algorithmic, and autonomous minds: Is it time for a triprocess theory?", In Two Minds: Dual Processes and Beyond, pp. 55-88.

Tan, T., Zou, H., Chen, C. and Luo, J. (2015), "Mind wandering and the incubation effect in insight problem solving”, Creativity Research Journal, Vol. 27 No. 4, pp. 375-382.

Valgeirsdottir, D. and Onarheim, B. (2017), "Metacognition in creativity: Process awareness used to facilitate the creative process", In: Christensen, B.T. and Ball, L.J. (Eds.), Analysing Design Thinking: Studies of Cross-Cultural Co-Creation, CRC Press, London, UK, pp. 215-228.

Valgeirsdottir, D., Onarheim, B. and Li-Ying, J. (2016), "Improving creativity training: A study of designer skills”, Design Vol. 2016, Design Society, Dubrovnik, Croatia, pp. 1175-1184.

Vermaas, P.E. (2016), "A logical critique of the expert position in design research: beyond expert justification of design methods and towards empirical validation”, Design Science, Vol. 2 No. May, p. e7.

Wacker, J.G. (1998), “A definition of theory: Research guidelines for different theory-building research methods in operations management", Journal of Operations Management, Vol. 16 No. 4, pp. 361-385.

Welling, H. (2007), "Four mental operations in creative cognition: The importance of abstraction", Creativity Research Journal, Taylor \& Francis, Vol. 19 No. 2-3, pp. 163-177. 